\title{
QUALITY CERTIFICATION IN THE VIRTUAL ENTERPRISE: AN OBJECTIVE TOOL FOR SUPPLY CHAIN MANAGEMENT AND CUSTOMER SATISFACTION
}

\author{
Ângelo Martins, J. J. Pinto Ferreira, J.M. Mendonça \\ ISEP (amartins@dei.isep.ipp.pt) \\ FEUP-DEEC/INESC Porto \\ FEUP-DEEC / Agência de Inovação \\ PORTUGAL
}

\begin{abstract}
In the scope of virtual and networked enterprises, we propose a way to integrate quality management into enterprise modeling and allow for quality certification of the whole enterprise. ISO 9001:2000 is presented as a suitable standard for these enterprises quality management systems implementation. On the other hand, quality management system certification in the scope of ISO 10011 is quite difficult, being presented some alternative scenarios for certification.
\end{abstract}

\section{INTRODUCTION}

The Global Supply Chain Forum (Lambert, 1999) defines Supply Chain Management (SCM) as: "SCM is the integration of key business processes from end users through original suppliers that provides products, services, and information that add value for customers and other stakeholders". For a company to control the product or service (or both) it offers to the customer, it has to completely control its supply chain. It's no easy task, and only with heavy bargain power can this be achieved. That is the case of the auto industry, where manufactures imposed systems for information exchange (manly EDI-Electronic Data Interchange) and a universal quality control system (QS-9000) on its suppliers.

One example of an organizational structure where the organization is built around the supply chain is the Virtual Enterprise (VE): " $A$ virtual enterprise is a temporary alliance of enterprises that come together to share skills or core competencies and resources in order to better respond to business opportunities, and whose co-operation is supported by computer networks" (Camarinha-Matos, 1999). One aspect that must be carefully evaluated is quality assurance. We believe this is very important subject related to VE for three main reasons:

- The widespread use of quality as marketing tool, and not only as a management tool.

- The mandatory use of quality certified suppliers in some business areas. 
- The need for an objective unbiased tool for both partner operation and customer satisfaction evaluation.

- The need for an objective unbiased tool for both partner operation and customer satisfaction evaluation.

In the specific case of the VE, there is also the natural mistrust customers may regard the VE, because of its innovative structure. Building the VE around a certified quality assurance system is indeed a way to overcome customers' lack of confidence and to open new markets.

One important characteristic of the VE environment is its continuous change (figure 1). In a VE, partner search and selection is not limited to the creation phase, but it may happen often during its lifetime, with extensive changes to the supply chain. This may result from unexpected events, such as a VE member failing to fulfill its obligations, thus having to be replaced; or resulting from the natural evolution of the VE. Actually, partner selection may be seen as a special case of general procurement, where the supplier requirements are more stringent and that VE structure will itself change, according to supplier's characteristics.

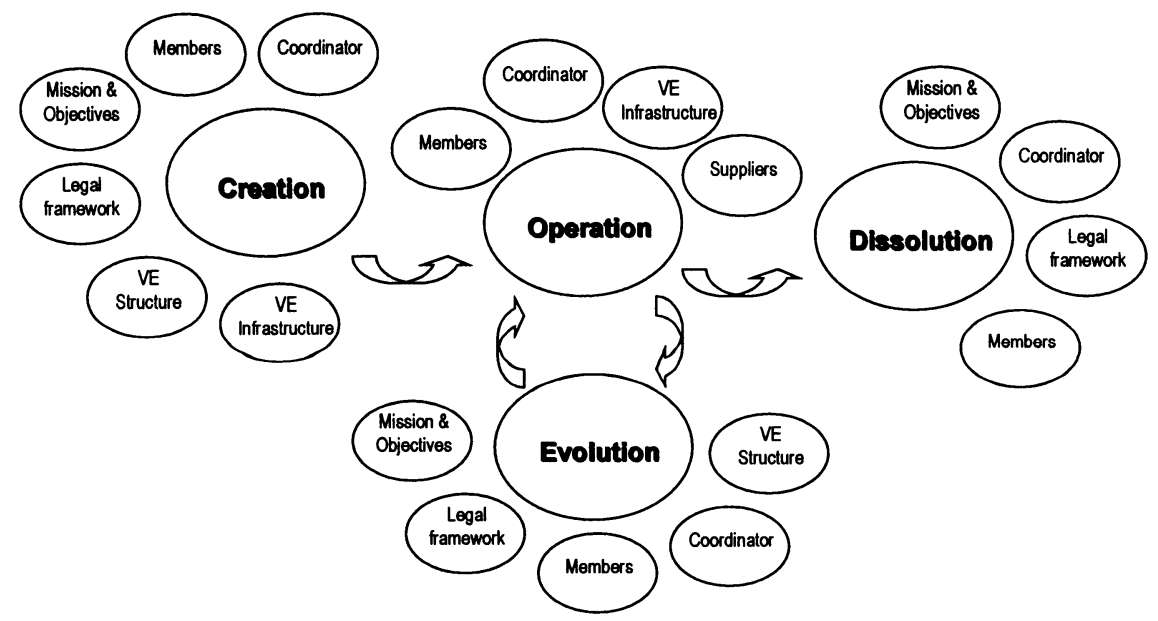

Figure 1 - VE life cycle, adapted from (Camarinha-Matos, 1999)

\section{VE MODELLING}

Figure 2 illustrates how, according to the so-called Purdue Enterprise Reference Architecture (PERA), an enterprise engineering project life cycle may unfold. The PERA life-cycle starts with Identification phase of the CIM Business Entity, leading to the first description of the management's mission, vision and values the for that entity plus any further philosophies of operation or mandated actions concerning it, such as choice of processes, vendor selection, etc. From the management mission, vision, etc., the operational policies for the units for all areas of potential concern are derived in the Concept Phase. The earlier prescription and selection by the management of possible options leads to the establishment of operational requirements for the manufacturing plant, which in turn lead to a statement of the 
requirements for all equipment and for all methods of operation which are developed along the Definition Phase. It should finally be noted that there are only two types of requirements, those defining information-processing tasks and those defining physical operation tasks. These tasks become collected into modules or functions, and these can in turn be connected into networks of information or of material and energy flow, resulting in the Information Functional Network or in the Operations Functional Network.

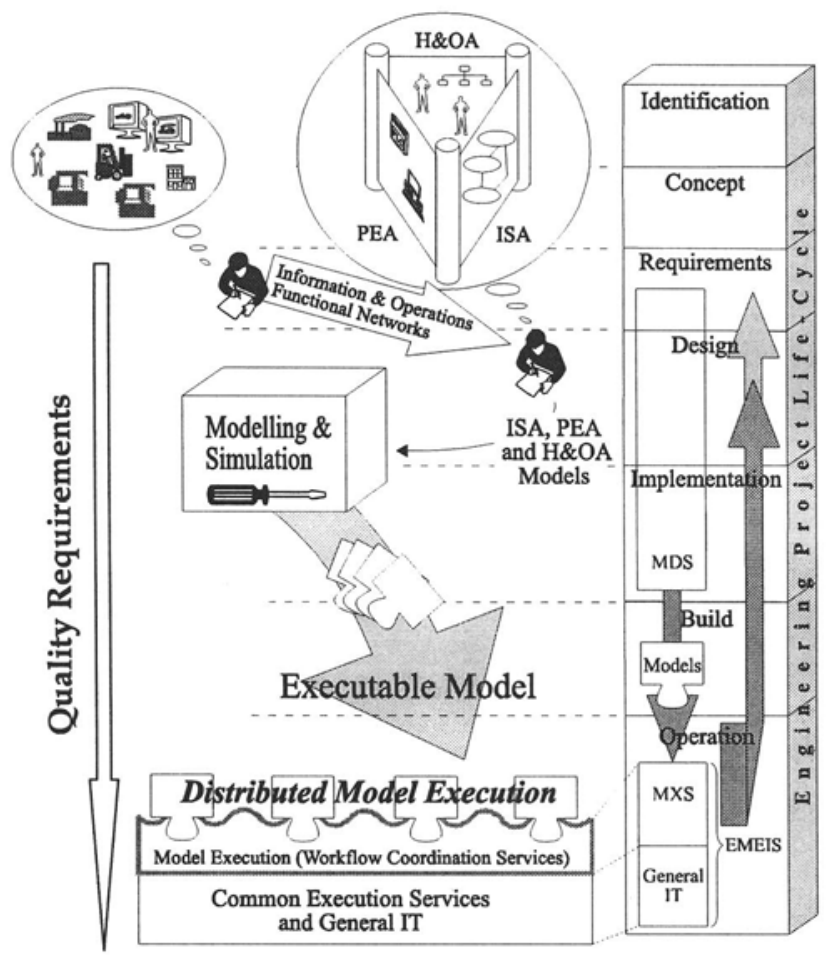

Figure 2 - VE Engineering Life cycle (Pinto Ferreira, 1999)

No consideration of the place of the humans in the system has been made yet. PERA nevertheless recognizes that in any enterprise development program, the human and organizational system is as important as the information system and physical components. This means that, once the implementation is considered, the first need is to define which tasks on either side of the overall architecture people will fulfill. Accordingly, three Implementation or Physical Architectures are introduced into the engineering project. These are (in figure 2):

- the Information System Architecture (ISA), (comprising the description of all infrastructure and application software, as well as their integration);

- the Human and Organizational Architecture (H\&OA), (encompassing the role played by operators in the each of their working places, as well as their integration into the overall organization so that enterprise objectives can be achieved); 
- and the Physical Equipment Architecture (PEA), (referring to the actual physical system architecture, such as computing, networking, manufacturing equipment).

Figure 2 also explores the model enactment concept. The Enterprise Model Execution and Integration Services (EMEIS), needed to provide the functionalities required in enterprise engineering for creating and using enterprise models. In this context, we refer to the Model Development Services (MDS) to support the development, analysis, management and release of model components, partial models and executable particular models of business entities of some enterprise. We also refer to the Model Execution Services (MXS) to provide for the operational use of models, and finally to the general IT Services. As illustrated, the Modeling and Simulation tool is clearly classified as part of the MDS. Further analysis of Figure 2 will reveal the relation between existing workflow co-ordination and the MXS, responsible for the actual released model execution.

\section{QUALITY AND THE VE}

Never before there was such awareness about quality as there is today, and the ISO 9000 set of standards is the most widely known. This set was created in 1987 under ISO (International Organization for Standardization), and is scheduled a major revision by the end of 2000. It is composed by quite a few standards, but this new revision will achieve some consolidation, being ISO 9001:2000 and 9004:2000 the most interesting in the scope of VE. The first one defines the basic rules and requirements for a QMS implementation, while the former has a broader focus, stressing quality improvement and other stakeholders' role (not only clients) in the enterprise. Given its popularity, ISO 9001:2000 should be considered when developing a QMS for the VE, though we must recognize that some improvements/changes should be considered.

In the VE world, we believe quality, and especially QMS certification, could be an interesting way to remove some of the barriers that hinder VE expansion as an alternative enterprise structure. One of these is the natural lack of trust in a type of organization with a shaky legal basement, whose motto is actually to be "shortlived". Actually, as most western countries base their legal systems on code law (UK and USA are exceptions, using a mix of code and case law), there isn't yet a wellestablished legal environment for VE operation, what further complicates VE development. Perhaps only when there is a sizeable number of well succeeded VEs (a critical mass) some of these fears will go away.

\section{ISO 9001:2000 DIS IN THE VE}

While VE operation is not conceptually different from a common enterprise one, the same may not be said about VE management. In a common enterprise, there is a clear definition of management responsibility, well understood by both internal and external stakeholders, while in the VE management/co-ordination responsibilities will be implementation dependent. One may consider two basic types of management/co-ordination: 
- Dominant, as in a common enterprise, more likely to happen when there is a dominant member in the VE. In this case, management and co-ordination are centralized in the same entity.

- Weak, focusing in VE operation management and co-ordination. Strategic management will be a common responsibility of all members, through some kind of agreed mechanism. In this case, VE co-ordination can be achieved through outsourcing, including co-ordination rules and methods in the VE model.

As seen above, Management seen as the operational representative of shareholders, is still true in the VE, only its role may be distributed over several entities. To meet the standard requirements, we believe it will be enough to present a clear definition of a management structure with enough authority to implement every of ISO 9001:2000 requirements. Yet on the management issue, ISO 9000 standards focus on enterprise evolution through quality improvement, and it's not considered the enterprise whole life cycle (figure 1). Though quality management system design may be considered when some new enterprises are created, that isn't certainly the case for most small and medium enterprises. It's only when the enterprise is fully operational and working that QMS implementation is considered. Actually, most certification bodies define a mandatory QMS operation period (a few months) prior to its certification. If quality is to be of any use in the VE, then it must be considered since its creation. We believe the best way to accomplish this is to include quality requirements in the development of enterprise models. Moreover, enterprise models should model the four phases of the VE life cycle (We have here the typical chicken and egg problem, but we will elaborate on this later!). Being a VE a temporary enterprise, it looks mandatory to define post mortem guarantees to clients, liabilities, etc. Anyway, even before its termination VE may evolve, perhaps considerably, so for the same reasons as for termination, the management of evolution has also to be explicitly modeled and included in the QMS.

In ISO 9001:2000, some relevance is given to resource management. Contrary to common enterprises, VE hasn't itself human or operation resources, being these modeled as functional entities of member enterprises. This way VE resource management would be a bit out of scope in the VE environment. However, it may not be the case, depending on the type of VE operation management perspective:

- type 1, each member makes available some functional operations and associated processing capacity distribution in time, which is used by VE production planning entity (or entities). Members do actual resource allocation to the VE according to its requests.

- type 2, each member makes available some functional entities or resources and associated processing capacity distribution in time, which is used by VE production planning entity (or entities) to do actual resource allocation.

Type 2 may be used whenever functional entity output is dependent on the entity itself, e.g. artistic or creative work, and VE management is much more complicated. If type 1 is used, then human resource management, from quality point of view, it is very much simplified and can be included in external suppliers management (item 6.6 in ISO 9004:2000 DIS) or even in purchasing control (item 7.4.1 in ISO 9001:2000 DIS). The easier way to handle procurement and member resources management would be to choose only quality certified members and suppliers. This would hardly be reasonable, so member and supplier management should be clearly 
modeled in the QMS, including member/supplier evaluation mechanisms. We even believe that quality could be an interesting tool for VE member management, especially because it may supply performance evaluation metrics, including those related to customer satisfaction.

VE operation and operation control should easily meet quality standards requirements, as the modeling infrastructure that supports VE design and operation requires a complete description of the VE. Nevertheless, some extra care must be taken to guarantee that every functional entity is qualified to execute its activities and that it has all resources and information necessary to execute the activity. Still regarding VE operation, distinction between member and supplier may not be very clear, and the lesser the distinction the more agile the VE should be (Goranson, 1999). From quality point of view, it is quite irrelevant if there is any distinction, since there must be control mechanism for both. As every activity is executed by outside entities, there must be activity input and output quality control mechanisms, which may be done by the executing entities themselves, if deemed qualified. Though this may look a heavy burden to VE operation, it is difficult to imagine how to control product/service quality through the supply chain without these mechanisms. On top of that, being the VE a co-operation environment, activity level product/service quality controls generate data that can be used for supply chain management and member/supplier evaluation.

ISO 9001:2000 clearly states that the QMS should be continually improved (item 8.5.1 Planning for Continual Improvement), being this improvement planed and managed according to quality policy, objectives and performance data. On top of quality improvement and changing client requirements, VE evolution may have other reasons (e.g. member replacement), and may even result in the decision to terminate VE operation. Though is not in even mention in the standard, ordered dissolution of the VE should be planned and controlled. Up till now, we haven't find big obstacles regarding the implementation of an ISO 9001 compliant QMS in the VE. In fact, the structured VE environment looks like a natural place for a QMS implementation. Nevertheless, we believe some requirements should be included in ISO 9001 (or a complementary standard/guideline) regarding VE life cycle. But if one of our objectives is to achieve QMS certification, in the VE environment this is not simple...

\section{CERTIFICATION}

To guarantee ISO 9001 compliance of a QMS, a certification body (CF) is used. Roughly, the process goes through three steps (The European Standard EN 45012 contains general criteria for certification bodies operating quality systems certification):

- CF information gathering about the enterprise (usually through questionnaires answered by the enterprise itself) and Quality Manual analysis;

- Auditing of the QMS and related quality records (ISO 10011);

- Certificate awarding, or not.

Once a certificate is awarded, there are follow-up audits (usually once a year) and major revision audits (perhaps every three years) to guarantee continued compliance with the standard. ISO 10011 is the international standard used for quality systems 
auditing (It will soon be replaced by ISO 19011). The auditing process and requirements defined in this three-part standard is definitely oriented for common enterprise auditing. VE auditing process must be much more dynamic, as the VE itself, so that compliance certificate may have any meaning (With the traditional process, it could easily happen that the certificate could be void even before it was issued!). It isn't our intention to propose here a new auditing standard for VE type organizations, but we have identified four requirements critical for VE quality certification:

i. VE functional entities must meet QMS requirements;

ii. The complete VE operation should be modeled into the QMS;

iii. The complete VE life cycle should be modeled into the QMS;

iv. Continuous auditing of the VE QMS by an independent trustworthy entity (certification body).

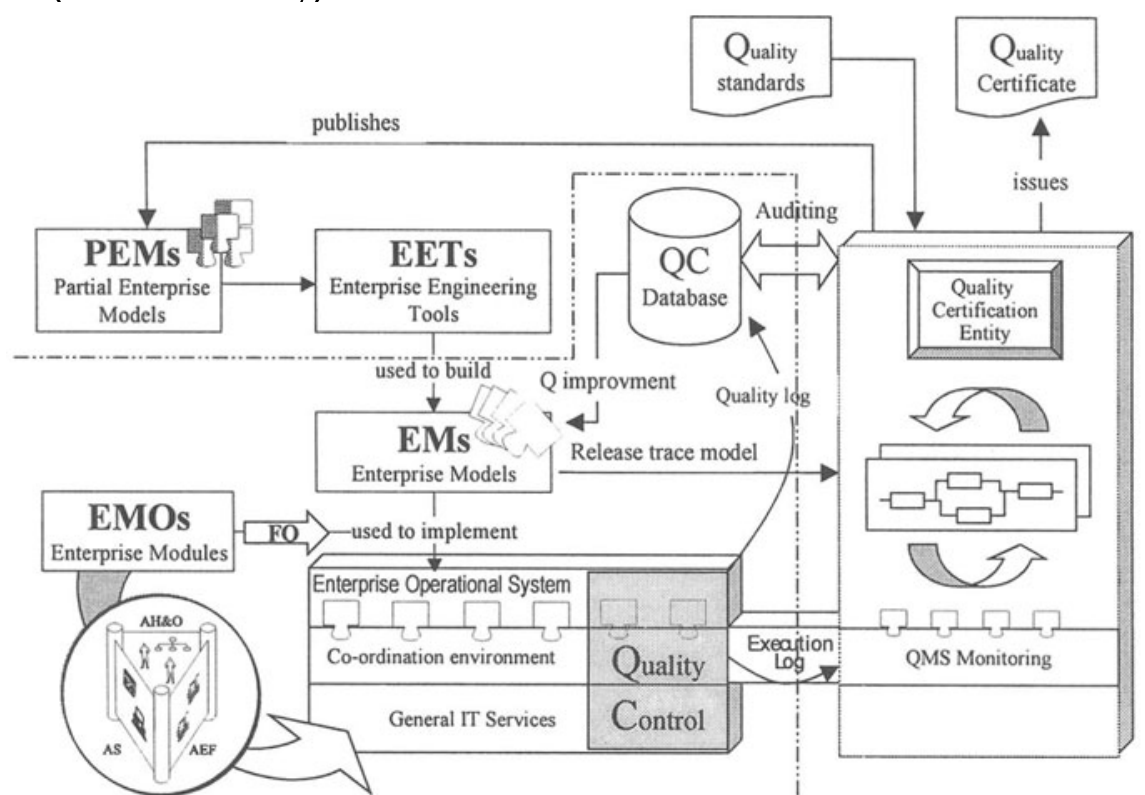

\section{Virtual Enterprise $\quad$ Environment}

Figure 3 - VE quality certification scenario (Martins, 2000)

Items one through three result from the above discussion about the ISO 9001:2000 in the VE. An interesting way to meet the first requirement is to have only quality certified members (and suppliers too, if possible), especially if a member is itself a VE. This will not always be possible and procedures for member/supplier management must guarantee the desired product/service quality and preservation along the supply chain. Item four is perhaps the key to VE certification. It's completely different from current auditing methods (ISO 10011), but we believe that, due to the agility of VE environment, it's the way to guarantee continuous compliance with the standard. To achieve this, VE's operational system encompassing the so-called EMEIS (Enterprise model execution and integration services) will have to allow for the CF to continuously monitor VE operation, in real time, if necessary (figure 3). EV models should provide multiple detail levels, being 
one level the QMS model (for quality purposes, detailed physical interactions aren't necessary), which the CF monitors. VE operational system integration with the CF doesn't look a complicated matter (e.g. using the Internet) and we define three levels (increasing integration):

i. Simple remote access to the QMS model and quality records (including QMS model execution log). Auditing is done periodically and not in real time. It may prove enough for static or near static VEs.

ii. Asynchronous monitoring. In this case, a QMS model image may even be stored at the CF (quality records stay always at the enterprise), having the CF periodic access to QMS execution log. This log allows for the synchronization of the QMS model image with the QMS model (trace driven simulation) and for a complete auditing of the VE (remote access to quality records will be necessary at times). The VE managing entity may be notified of any deviation or nonconformity detected, allowing for a better VE management.

iii. Synchronous monitoring. A QMS model image may be stored at the CF or be accessed remotely, having the CF permanent access to the VE QMS and quality records. This allows for real-time reaction to deviation or nonconformity, what may be critical in some cases.

The several types of monitoring might result in different certification levels. And in the last case, the CF could also act as the monitoring entity of the VE, or even the supplier of the operational system for VE operation. Finally, for VE quality certificate and rating to be used in electronic marketplaces for partner/supplier selection, some security mechanisms must be enforced to guarantee that certificates are authentic.

\section{CONCLUSION}

We presented a scenario for integrating quality management into the VE world, using the ISO 9001:2000 standard, and for QMS compliance certification. While the former may be achieved, QMS certification isn't quite possible with current certification procedures. As a result, new requirement we presented, including the continuous monitoring of the QMS model by the certification body.

\section{REFERENCES}

1 Lambert, Douglas M., et al (1998). Supply Chain Management: Implementation Issues and Research Opportunities, The International Journal of Logistics Management, Volume 9, Number 2

2 Camarinha-Matos, L. M., et al (1999). The virtual enterprise concept, Infrastructures for Virtual Enterprises - Networking Industrial Enterprises, L. M. Camarinha-Matos and Hamideh Afsarmanesh Ed, Kluwer Academic Publishers

3 Pinto Ferreira, J.J. (1999). From Manufacturing Systems Simulation to Model-based activity coordination, CARS\&FOF'99, Brazil, 1999

4 Goranson, H. T. (1999). The Agile Virtual Enterprise - Cases, Metrics, Tools, Quorum Books

5 IFIP - IFAC Task Force. GERAM - Generalized Enterprise Reference Architecture and Methodology, Version 1.6

6 ISO - International Organization for Standardization, http://www.iso.ch

7 Martins, Angelo, Mendonça, J. M. (2000). Qualidade e Certificação na Empresa Virtual (Quality Certification in the Virtual Enterprise), presented in the $1^{\circ}$ Congresso Nacional da Qualidade 2000, Lisboa, Portugal 